\title{
IDENTIDADES, GÊNEROS, SEXUALIDADE E VELHICE em “Marieta e Ferdinando”, de SÉrgio Sant'Anna
}

\author{
Identities, genres, sexuality and old age in "Marieta \\ e Ferdinando", by Sérgio Sant'Anna
}

\author{
Rafael Magno de Paula Costa ${ }^{1}$ \\ ${ }^{1}$ Secretaria de Educação do Estado Paraná. Paranaguá, PR, Brasil. \\ E-mail: rafaelmpc82@hotmail.com
}

\section{RESUMO}

A partir da análise do conto "Marieta e Ferdinando", investiga-se a composição dos estereótipos masculino e feminino como produtos de condições sociais que determinam certas práticas. $\mathrm{O}$ conto reflete sobre um casamento prolongado em que o casal, em especial a mulher, sofre com o desgaste e com a transformação de seus corpos. O relacionamento em declínio proporciona uma fusão entre os atributos que compõe a experiência entre gêneros das personagens. Os papéis desempenhados por cada um sofrem, ao final do conto, uma troca ou transmutação, afetando inclusive seus corpos. Desse modo, verifica-se como a luta constante pelo exercício da sexualidade e pela manutenção da juventude do corpo são fatores que desvelam a artificialidade de determinados padrões de gênero como algo socialmente construído.

EDITOR-CHEFE:

Gerson Roberto Neumann

EDITOR EXECUTIVO:

Regina Zilberman

SUBMETIDO: 30.04 .2021

ACEITO: 15.06 .2021

\section{COMO CITAR:}

COSTA, Rafael Magno

de Paula. Identidades,

gêneros, sexualidade e velhice em "Marieta e Ferdinando”, de Sérgio Sant'Anna. Revista Brasileira de Literatura Comparada, v. 23, n. 44, p. 192-202, set.dez., 2021. doi: https:// doi.org/10.1590/2596$304 \times 20212344 \mathrm{rmpc}$
Palavras-chave: identidades; gêneros; sexualidade; velhice; masculinidades.

\section{ABSTRACT}

From the analysis of the short story "Marieta e Ferdinando", it investigates the composition of male and female stereotypes as products of social conditions that determine certain practices. The short story reflects a prolonged marriage. The couple, especially the Woman, suffers from the wear and transformations of their bodies. The delining relationship provides a fusion between male and female characters' experiences. The roles played by each one, at the end of story, suffer a mutation affecting even their bodies. Thus, it is verified as the constant fight for the sexuality exercise and for the youth body maintenance are factors that show the artificiality of certain gender patterns.

KEYwORDs: identities; genders; sexuality; old age; masculinities. 


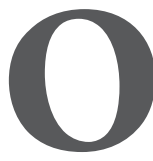
conto “Marieta e Ferdinando”, de Sérgio Sant’Anna, lançado pela primeira vez em 1973 na coletânea intitulada Notas de Manfredo Rangel, Repórter (a respeito de Kramer), narra a vida do casal que dá nome à narrativa. $\mathrm{O}$ conto propõe reflexões diversas como as identidades que caracterizam o casal, o exercício da sexualidade de cada um, o problema da velhice, bem como uma desconstrução sobre determinados papéis de gênero cristalizados, porém desconstruídos, ao final do conto. A relação a dois é demonstrada no modo como a troca dos papéis masculino e feminino promove uma reflexão sobre a artificialidade da construção social dos gêneros que envolvem ambas as personagens.

Narrado em terceira pessoa, o conto inicia-se com a descrição do cenário onde moram as personagens. $\mathrm{O}$ bairro apresenta sinais de decadência, visto que no passado havia sido um centro importante. O narrador descreve os prédios em estado de abandono, com as paredes rabiscadas. É nesse ambiente que Marieta e Ferdinando estabelecem sua relação:

\begin{abstract}
Ali, onde se pode entrar ao acaso num daqueles prédios de três ou quatro andares, e subir as escadas onde as luzes se queimaram e não foram substituídas, onde as paredes, marcadas a prego, carvão e lápis, falam de amores suspeitos e fantasias sexuais com ilustrações disformes, onde essas mesmas paredes - e também as frestas - conduzem livremente o som de gemidos, orgasmos, palavras pronunciadas durante os sonhos [...] ali, atrás de uma daquelas portas, é o território de gente como eles, o território deles: Marieta e Ferdinando. (SANT'ANNA, 1997, p. 111)
\end{abstract}

O cenário ajuda na compreensão sobre o ambiente em que o casal vive. Além da poluição visual provocada pelos rabiscos nas paredes sobre amores suspeitos juntos às fantasias sexuais, o narrador também descreve os sons de gemidos e orgasmos. Por conseguinte, ele abandona a descrição do cenário para focar em Marieta. A personagem encontra-se à espera do seu parceiro, Ferdinando, se preparando para recebê-lo:

São dez horas da noite e Marieta espera por Ferdinando, que até agora não veio. Marieta saiu do banho, vestiu seu melhor vestido para Ferdinando, mas Ferdinando não veio. Então Marieta está sentada, inútil, diante do espelho. Marieta ensaia vários sorrisos, Marieta repara num dente mais escuro - um dente sem nervo. Marieta franze a testa, preocupada, mas depois afasta seu pensamento para os cabelos. Há um modo de jogá-los sobre o rosto, escondendo os olhos, que torna Marieta mais misteriosa. Marieta continua se olhando no espelho e agora se concentra em sua pele. A pele vai se tornando empapuçada no rosto, flácida nos braços, no corpo inteiro. Marieta está ficando velha. Talvez por isso Ferdinando ainda não veio. (SANT'ANNA, 1997, p. 111-112)

A descrição da ansiedade de Marieta é importante, pois se associa aos pensamentos da personagem. Ao descrever detalhes minuciosos do corpo dela, o narrador revela o modo como a personagem sente essas transformações do tempo. A percepção da velhice por parte dela é relacionada à ausência de Ferdinando. A razão de ele ainda não ter chegado é justificada por meio dos pensamentos da personagem feminina que, ao constituir uma autoimagem degradante, entende que o marido procura permanecer distante dela. Os adjetivos que qualificam sua pele como "empapuçada" e "flácida", nesse sentido, são potentes em causar um sentimento de frustração por conta dessa passagem do tempo impressa no corpo da personagem. Assim, para ela, Ferdinando ainda não chegou porque possivelmente ele não a quer mais ou procura evitar sua companhia. Consequentemente, o narrador prossegue abordando os pensamentos de Marieta: 
Marieta se põe a pensar que Ferdinando se torna, a cada dia, mais distante. Ferdinando não diz mais, por exemplo, que a ama. Também não traz presentes, não faz nenhum desses pequenos gestos de carinho de que as mulheres tanto gostam, para sentirem-se valorizadas. Há quanto tempo Ferdinando não diz que ela é bonita? Marieta não consegue lembrar-se da última vez que Ferdinando lhe dirigiu um elogio. Nem mesmo uma dessas mentiras que ajudam a sustentar um casamento. (SANT'ANNA, 1997, p. 112)

Esse distanciamento do marido de Marieta, de algum modo, também aponta para o desgaste do relacionamento a dois. A personagem sente falta do amor de Ferdinando, visto que há muito tempo ele não diz que a ama. Tal sentimento, no caso de Marieta, parece não ter sofrido uma perda do desejo, mas no caso de Ferdinando sim. A ideia de que o amor sofre um desgaste significativo com o compromisso pode ser entendida como algo que afeta mais Ferdinando que Marieta. $\mathrm{O}$ desejo amoroso pode ter morrido por parte do homem, mas ainda sobrevive na mulher, o que demonstra uma postura diferente de cada gênero em relação ao amor.

A descrição da ausência de pequenos gestos de carinho, como trazer lembranças, por exemplo, cria a sensação de que o amor de Ferdinando entrou em declínio. Pequenas coisas, como a ausência de um elogio a sua mulher, também causam em Marieta uma sensação de angústia e um sentimento de desvalorização. Um elogio, por exemplo, ganha uma dimensão grande, pois é importante mesmo que seja uma mentira, neste caso. Desse modo, a narrativa propõe uma reflexão importante sobre a relação amorosa do casal que se encontra num estado de desgaste emocional.

Consequentemente, o narrador relata a tristeza que toma conta do estado de alma de Marieta: "Marieta pensa, agora, que envelhecer é uma merda. E duas lágrimas começam a brotar em seus olhos. Marieta está se olhando no espelho, observando as duas pequenas lágrimas que se formam nos olhos mas custam a pingar" (SANT'ANNA, 1997, p. 112). Essa tristeza se verifica na personagem a partir do inconformismo em não aceitar a velhice. Por outro lado, essa não aceitação pode ser entendida como uma luta entre a humanidade e a natureza das coisas (velhice). Isso explica, por exemplo, aquilo que Bruckner pontua como uma sociedade que vive pelas normas da formosura e da juventude. Assim, Marieta pauta sua aparência dentro dessas normas e, por esse motivo, se sente mal, inferior e envelhecida.

Pascal Bruckner, em O paradoxo amoroso, aponta para o modo como essa constante e permanente luta contra a velhice se associa à procura pelo prazer, o que, por sua vez, gerou outro fenômeno curioso: o sexo como produto. Tratamentos, terapias, remédios, práticas orientais - tantrismo e abertura de chakras - e sex shops exploram o potencial comercial que o sexo pode ter. Segundo ele, o maior medo dos casais modernos é ver suas relações degenerarem em dois eunucos impossibilitados da prática sexual em razão dos fatores biológicos. Esse medo encontra-se em Marieta. $\mathrm{O}$ tempo exerce implacavelmente sobre ela o seu poder de dissolução.

A sexualidade, assim, tem prazo de validade, mas muitos pretendem prolongar sua juventude: "Mesmo os temperamentos fogosos acabam um dia esfriando. [...] Não é o outro que é preciso acusar, pobre humano como eu, é a fraqueza de nossa constituição. A sexualidade durável é uma das utopias mais patéticas do mundo moderno" (BRUCKNER, 2014, p. 109). A castidade, forçada pela velhice, torna-se um empecilho fatal para o exercício da atividade sexual ao sujeito contemporâneo, em razão do inevitável desgaste, do consequente desinteresse sexual e do esgotamento do desejo.

$\mathrm{O}$ amor, desse modo, ao ser associado à sexualidade, pode ser compreendido como uma busca por vitalidade, em ser ou sentir-se jovem. Essa procura constante pela juventude cria uma conotação 
de amor que exclui o processo natural de envelhecimento humano. Neste caso, Marieta não aceita sua condição, pois para ela sua beleza, alterada pelo envelhecimento, não se enquadra nesses padrões preconizados pela sociedade de consumo. A atitude mais comum na atualidade seria lutar contra a velhice, depreendida, de alguma maneira, como algo negativo. Essa luta contra a senilidade atualmente se traduz também em bens de consumo como, por exemplo, cremes que combatem a flacidez, cirurgias plásticas, etc.

O conto provoca, assim, uma reflexão sobre a condição da velhice ou do amor como um atributo exclusivo de juventude. Isso não quer dizer que amor seja algo que deva ser interditado às pessoas mais idosas, mas sim que o amor, de algum modo, passa a ser entendido como um sentimento que cria uma sensação maior de ânimo e vida, consequentemente fazendo com que o sujeito se sinta mais jovem. A ausência de amor, contudo, produz efeito contrário, ou seja, cria uma sensação de velhice, desgaste e morte. É preciso, no entanto, ponderar que isso é um mito artificial criado pela sociedade de consumo, seja para preconizar uma sociedade de eternos jovens ou mesmo para movimentar o consumo de produtos ou tratamentos de rejuvenescimento.

Essa tristeza é ainda acentuada quando em frente ao espelho Marieta faz careta e profere palavras sem lógica: “'Estou ficando louca?', Marieta pensa, satisfeita com a ideia. A loucura é algo romântico. Mais romântico, por exemplo, do que a velhice. Um velho louco não é tão deprimente quanto um velho apenas velho. Um velho doente" (SANT'ANNA, 1997, p. 112). O tema da velhice ganha uma carga relevante no conto, pois a narração dos pensamentos de Marieta cria reflexões que pontuam o caráter triste e negativo do envelhecimento. Não que a velhice seja necessariamente negativa, mas é importante observar como Marieta compreende esse processo de transformação na sua vida.

A loucura também contribui para essa fuga da realidade. A realidade da velhice para a personagem pode se tornar insuportável ao ponto de apelar para a loucura. De fato, o caráter escapista da loucura indica que Marieta busca uma evasão dessa realidade. Essa atitude dela equivale a uma atitude romântica, naquilo que os românticos do século XIX entendiam como fugir de um presente insuportável. Por isso, a loucura, para ela, se configura como uma possibilidade de vivenciar coisas diferentes daquelas corriqueiras, banais e rotineiras.

Assim, o narrador onisciente mergulha nos pensamentos de Marieta sem, entretanto, fazer qualquer juízo de valor sobre eles, ficando no campo meramente descritivo. Essa neutralidade do narrador indica que os pensamentos são produtos da mente da personagem, embora mediados pela narração em terceira pessoa. Na sequência, o narrador foca a maneira como Marieta enxerga seu marido:

\footnotetext{
Do mesmo modo que ela sabe muito bem o que Ferdinando faz quando na rua. Envolvendo-se em brigas, botequins e jogos de baralho. Ferdinando que, agora, depois que os anos se passaram chega em casa praguejando e com o hálito fedendo a cebola, cigarro barato e álcool. Ferdinando que chega em casa tarde, embora respeitando, sempre, o pacto da meia-noite. Ferdinando deve estar para chegar e não adianta fazer perguntas, não há necessidade de perguntas, porque Marieta sabe bem o que Ferdinando faz na rua. (SANT'ANNA, 1997, p. 112)
}

Se observarmos, o narrador, nessa citação, inicia comentando sobre a rua e termina no mesmo ponto. Marieta sabe o que Ferdinando faz, no entanto, não está claro o que seja. O narrador deixa subentendido. Embora se descreva que Ferdinando estava nos botequins jogando baralho e bebendo, essa expressão no final "Marieta sabe bem o que Ferdinando faz na rua” parece estar apontando 
ironicamente para uma possível infidelidade. Porém, é preciso ratificar que o texto não expressa nem mesmo deixa pistas mais evidentes sobre essa questão.

Outro detalhe importante é a expressão utilizada pelo narrador "depois que os anos se passaram". Essa expressão ganha uma carga semântica no sentido de que aponta para uma relação estabelecida há muito tempo. Isso demonstra que a relação do casal é estável e de longo prazo. A construção de Marieta como uma esposa maturada pelo tempo e que espera pelo marido também parece indicar que ela não se constitui como uma mulher emancipada do espectro masculino. A maneira como Marieta se conforma em não ter que fazer perguntas sobre onde o marido esteve ou com quem esteve apontam para esse detalhe. A construção narrativa de Ferdinando, por outro lado, também é interessante como um contraste em relação à Marieta:

Ferdinando trabalha em biscates, eletricista, bombeiro, mecânico, encerador, qualquer negócio que apareça, até mesmo algum pequeno furto eventual. Ferdinando que se deixa ficar, desanimado, examinando um cano para desentupir. Ferdinando que sai assobiando, satisfeito, depois que terminou um serviço e ganhou vinte cruzeiros e pensa que agora já pode ir ao botequim. Sem lembrar que ela o espera em casa, Marieta. Ferdinando que pensa que é dura essa vida de biscateiro. Ferdinando que pensa que é dura essa vida de homem. E Ferdinando pensa que a vida de mulher, apesar de algumas aporrinhações, é bem mais fácil. Ficar em casa, à toa, esperando (SANT’ANNA, 1997, p. 112-113).

A imagem de Ferdinando se caracteriza por meio dos seus pensamentos sobre a vida e sobre sua relação. Ele, um representante da classe trabalhadora, é apresentado como um sujeito que pensa que a vida das mulheres é fácil porque ficam em casa “à toa”. Esse pensamento, portanto, confirma que se por um lado Marieta é constituída como uma personagem feminina de um tempo em que a maior parte das mulheres permanecia em casa, por outro lado, Ferdinando é construído como um sujeito que acredita que seu papel seja o de prover a vida do casal e, consequentemente, a mulher precisa estar em casa. Isso explica a razão do pensamento masculino que imagina que a vida doméstica seja melhor que a vida no trabalho fora do lar, em razão do suposto “ócio". Entretanto, o que Ferdinando não vislumbra nessa reflexão, exposta pelo narrador, é que existe também trabalho no âmbito doméstico, embora, mais de uma vez é preciso afirmar, não seja reconhecido socialmente e, consequentemente, nem mesmo por ele. Ele não aventa, ainda, a possibilidade de sua esposa poder trabalhar fora do âmbito doméstico.

Desse modo, a relação do casal é transmitida como se houvesse um desgaste significativo do amor entre os dois. Essa sensação é transmitida pela sequência da narrativa:

Ferdinando que entrou em casa e não disse nem boa-noite para Marieta; não lhe deu um tapinha na bunda, como antigamente. Como um marido, Ferdinando chegou em casa, sentou-se na poltrona e abriu um jornal todo amassado. Assim são os homens depois que o amor se torna antigo, pensa Marieta, suspirando. Ouvindo o suspiro, Ferdinando levanta os olhos do jornal, vê Marieta e pensa que as mulheres são tolas e chatas. Assim são os homens e Ferdinando volta a se concentrar no jornal. (SANT'ANNA, 1997, p. 113)

O narrador contrasta os pensamentos de Marieta e Ferdinando possibilitando um jogo de imagens interessante. Primeiramente, a forma como o homem entra em casa sem dar boa noite evidencia a pouca importância que ele dá a um simples gesto de saudação. O narrador também é irônico quando compara a atitude de Ferdinando ao de qualquer marido, ao usar a expressão "como um marido", quando ele senta na poltrona para ler o jornal. $O$ uso da conjunção comparativa "como" aliada ao 
artigo indefinido "um" cria o efeito de comparação da ação de Ferdinando como se fosse a ação de qualquer marido. Deduz-se que a sua postura é equivalente à de "um marido", ou seja, o significado de ser marido é exatamente se portar como se o amor ou o simples afeto não existissem no casamento que se prolongou.

Essa reflexão é corroborada com o pensamento de Marieta pontuado pelo narrador: "assim são os homens depois que o amor se torna antigo". O conto, a partir dessa construção masculina de Ferdinando, conduz a uma leitura da relação conjugal que deixa o sentido da morte do amor subentendido. A rotina diária de uma relação a dois, por outro lado, transforma o amor em algo antigo, ou seja, envelhecido. Desse modo, a relação de longo prazo entre o casal demonstra um esfriamento do amor por parte de Ferdinando. Essa reflexão da esposa, por outro lado, leva o leitor a acreditar que ainda exista amor, carinho e afetividade por parte dela. Contudo, é um amor sem reciprocidade.

O prazer da relação é perdido e, consequentemente, o amor é marcado pelo adjetivo "antigo" que, por sua vez, expõe a passagem do tempo. $\mathrm{O}$ amor tornado antigo, assim, equivale a um amor envelhecido, desgastado e frio, em que um não sente mais pelo outro aquilo que em algum momento do passado sentia. Marieta tenta resgatar essa chama apagada quando pensa sobre a falência do seu relacionamento. Ferdinando, por outro lado, permanece aparentemente distante ou indiferente a esse sentimento. Sobre isso, Pascal Bruckner enfatiza, por exemplo, a ideia de que os obstáculos, de algum modo, garantem a sobrevivência do amor:

Amar o amor em geral mais do que os próprios seres é deleitar-se com um ideal. [...] Privado dos obstáculos que o vivificavam ao freá-lo, ei-lo obrigado a encontrar em si os meios de se renovar. Ele morre não por ter sido impedido, mas por ter sido tão bem-sucedido. A paixão, dizem, é irresistível; infelizmente ela resiste a tudo, salvo a si mesma. A tragédia clássica opunha uma ligação impossível a uma ordem cruel; na tragédia contemporânea, o amor é morto por ele mesmo, morrendo de sua própria vitória. É exercendo-se que ele se destrói, sua apoteose é seu declínio. (BRUCKNER, 2014, p. 111)

A “morte do amor" se explica em sua natureza contraditória, pois à medida que não há nada que impeça sua realização ou concretização, esse sentimento inicia sua derrocada rumo ao falecimento. A presença constante da pessoa amada, nesse caso, contribui para acentuar a falência de um dado relacionamento. A morte do amor pode ser explicada como decorrência da crescente proximidade de um determinado casal. Bauman, em Amor líquido, corrobora com essa noção de que o amor morre quando ele se realiza. De acordo com ele, o amor e a morte seriam experiências únicas que não se repetiriam: "poucas coisas se parecem tanto com a morte quanto amor realizado. Cada chegada de um dos dois é sempre única, mas também definitiva: não suporta a repetição, não permite recurso nem promete prorrogação" (BAUMAN, 2004, p. 16-17).

O amor, sendo uma experiência única, não passível de repetição, morreria em sua realização. Nesse sentido, Bauman utiliza-se das imagens de Eros e Tânatos para falar sobre essa proximidade do amor e da morte. Segundo ele, Eros quando finalmente triunfa é simultaneamente derrotado, pois, quando o amor atinge o seu fim automaticamente morre. À medida que o sujeito deseja ardentemente conquistar alguém, quando finalmente consegue êxito, o amor perde seu poder de encantamento:

Todo amor empenha-se em subjugar, mas quando triunfa encontra a derradeira derrota. Todo amor luta para enterrar as fontes de sua precariedade e incerteza, mas, se obtém êxito, logo começa a se enfraquecer - e definhar. Eros é possuído pelo fantasma de Tânatos, que nenhum encantamento mágico é capaz de exorcizar. (BAUMAN, 2004, p. 22) 
Por conseguinte, o perfil masculino de Ferdinando é retratado como um sujeito misógino que acredita que as mulheres são "tolas" e "chatas”. Embora não apresente violência física em suas ações, ele, ao ler uma notícia, sobre um crime de um homem que matou a amante a machadadas, pensa o seguinte: "Por um momento, Ferdinando imagina-se numa situação semelhante: matando Marieta a machadadas. Mas Ferdinando sabe que nunca fará isso: ele não teria coragem (apesar de certos impulsos às vezes) e além disso tem nojo de sangue" (SANT'ANNA, 1997, p. 113). O simples fato de conjecturar um crime coloca Ferdinando numa posição masculina degradante. O narrador ironiza esse pensamento, pois a maior razão que impede Ferdinando de matar a esposa a machadadas é seu nojo por sangue e não o afeto. Os pensamentos de Marieta são descritos levando o leitor a refletir sobre determinados papéis masculinos desempenhados por sujeitos como Ferdinando:

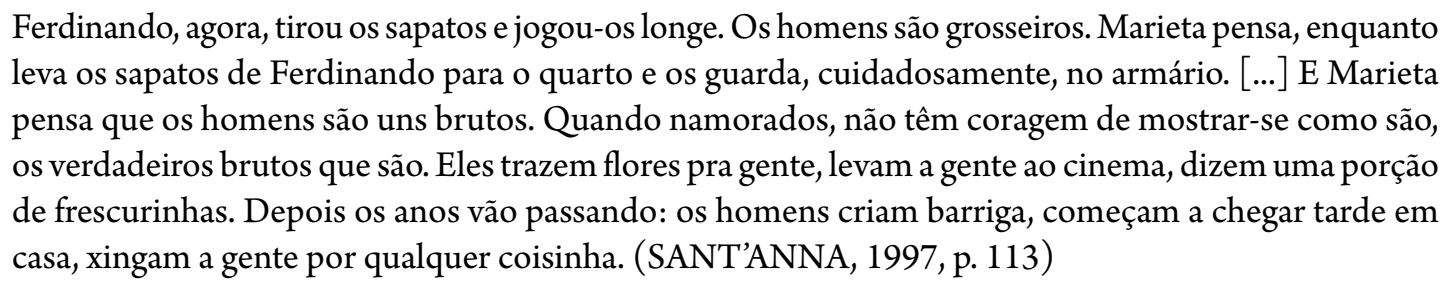

No início do conto, Marieta encontrava-se à espera de Ferdinando em frente ao espelho. Naquele local, Marieta tinha a sensação de que Ferdinando, mesmo ausente, estava ali a observando: "Marieta tem a sensação de que Ferdinando pode vê-la, mesmo ausente” (1997, p. 112). Esse espelho das mulheres pode ser entendido pela maneira como elas enxergam os homens, tal como teoriza Chistine Bard, em "A virilidade no espelho das mulheres". De acordo com a pesquisadora, a virilidade masculina é depreendida, em muitas situações, como uma ofensa às mulheres. Sobre o denominado "espelho das mulheres", Bard apresenta a seguinte análise:

O espelho, então, faz retornar aos homens uma imagem difícil de aceitar da - sua - virilidade: mortífera, belicista, criminosa, mutiladora... Para as feministas, a virilidade coincide agora com um comportamento sexista; ela expressa a dominação masculina (BARD, 2013, p. 117).

Assim, a masculinidade de Ferdinando se constrói, sobretudo, a partir das noções de brutalidade ("uns brutos") e grosseria ("xingam a gente") masculinas em relação aos sentimentos da sua esposa. Pelo menos é assim que a esposa percebe suas atitudes. As identidades masculina e feminina se constituem no conto a partir dessas noções em que as mulheres são estereotipadas como delicadas e afetuosas, que esperam pela atenção dos maridos, enquanto os homens são estereotipados como brutos, mal-educados e grosseiros. Os espaços também corroboram no sentido de que o homem sai para o trabalho fora do lar enquanto a esposa permanece em casa à espera dele.

A crítica que Marieta faz ao processo de envelhecimento do seu marido também é significativa, visto que "criar barriga" aponta para uma queda na vaidade, que se explica em razão do homem não esperar por mais nada da vida. Na linha de raciocínio do marido, não é preciso conquistar Marieta, pois ela já está ao seu lado. Também não é preciso reconquistá-la, pois não a perdeu. Assim, Ferdinando permanece acomodado em sua zona de conforto. Nesse sentido, ele, além de não esperar nada, também não dá importância a quem está ao seu lado. Desse modo, o amor, entendido como um vínculo afetivo, para o casal, encontra-se apático, letárgico ou mesmo morto. 
A falta de atenção do marido também é outro dado que corrobora com a indiferença masculina: "Desde que chegou, não disse uma palavra. Não reparou que ela pôs o melhor vestido e se arrumou toda para ele. Não perguntou nem mesmo por comida, porque deve ter comido porcarias na rua" (SANT’ANNA, 1997, p. 113-114). Além desse tratamento frio, Ferdinando também: “irá deitar-se no quarto e roncar como um porco" (1997, p. 114). Desse modo, a carência afetiva pela qual atravessa Marieta é acentuada por essa frieza e indiferença, ou ainda, pela pouca importância que o marido dá à esposa. O narrador esboça os pensamentos da mulher que refletem esse perfil de Ferdinando:

\begin{abstract}
Marieta vem para o quarto e repara que Ferdinando está lendo outra vez. Não adiantou nada ela colocar o vestido bacana e fazer o cabelo e perfumar-se. Ferdinando não prestou a menor atenção. Marieta, agora, tira o vestido na frente de Ferdinando, que nem assim desvia os olhos da revista. Marieta fica pensando que um casamento velho é sempre uma ligação de conveniência. As pessoas permanecem juntas para não ficarem sozinhas, eis tudo. Até as brigas perdem aquele ardor do princípio, quando ela e Ferdinando chegavam a trocar tapas. Sim tapas. O que existe, agora, é acomodação e indiferença. Eles dois - Marieta e Ferdinando - que juraram amor eterno, não diante de um juiz ou padre, porque não são verdadeiramente casados. (SANT’ANNA, 1997, p. 114)
\end{abstract}

O medo da solidão é um sentimento que explica a permanência do casal mesmo após o amor ter desaparecido. Com efeito, permanecer juntos durante muito tempo é entendido por Marieta como uma forma de não se sentir só. Por outro lado, mesmo a presença de Ferdinando não aplaca esse sentimento de solidão que é perceptível em Marieta.

Outra informação importante, colocada aqui, menciona sobre as brigas que perderam suas motivações. As brigas, embora sejam ações consideradas negativas, neste caso, são vistas com certo saudosismo, pois a esposa sente falta delas em razão de como poderiam significar um amor vivo no relacionamento. Essa carência do amor faz com que Marieta pense "um casamento velho é sempre uma ligação de conveniência”. Isso evidencia uma noção pessimista sobre a instituição em questão, como se o sentido de um casamento de longa durabilidade se tornasse sempre uma questão de conveniência. A rotina do casamento é apresentada como um fator que esmaga os ânimos de Marieta. Apesar disso, ela não cobra por uma mudança de atitude por parte de Ferdinando, apenas sofre calada e pensativa.

O juramento de amor eterno também contribui para que o casal permaneça junto. Valores como lealdade ou fidelidade à palavra dada podem ser um indício dessa permanência aparentemente a contragosto. Mesmo que tal juramento não tenha sido feito diante da lei ou da religião, ou que não sejam "verdadeiramente casados", como afirma o narrador, Marieta entende que essas juras são importantes para a sua relação. $\mathrm{O}$ conto, desse modo, contribui para uma reflexão no sentido de depreender a falência desse modelo de relacionamento. De fato, o amor no casamento parece não fazer mais sentido, ao menos para Ferdinando, embora Marieta tente, a todo o momento, recriar novos sentidos para a relação. Consequentemente, recebe como recompensa apenas a indiferença de Ferdinando.

Outra estudiosa do assunto, que relaciona o problema da relação entre homens e mulheres, é a socióloga brasileira Maria Isabel Mendes de Almeida. Em seu trabalho intitulado Masculino/feminino: tensão insolúvel, no subcapítulo "A relação eu/outro", ela desenvolveu uma série de entrevistas com homens casados em seus relacionamentos e chega à seguinte constatação:

Vale a pena registrar que falar sobre a manutenção do par sexo e amor entre homens da geração dos que entrevistei, após uma experiência de relacionamento prolongada, resulta em estados mentais ou 
em visões retrospectivas não muito alentadoras. [...] a impressão que me ficou desta reflexão foi a de uma espécie de "trator" do tempo que, em geral, tudo devora e aplaina, condenando o relacionamento a uma busca meio melancólica de estratégias de sobrevivência. (ALMEIDA, 1996, p. 117)

Esse dado demonstra como a maior parte dos relacionamentos, após períodos relativamente longos entra em declínio. O símbolo utilizado pela socióloga como "trator do tempo" é ilustrativo em relacionamentos como o de Marieta e seu marido. Com efeito, os diálogos entre ambos evidenciam tal desgaste no que tange a uma relação amorosa num sentido mais rigoroso. De certo modo, essa atitude diante dessa paixão demonstra como muitos homens, com o perfil semelhante ao de Ferdinando, se relacionam com esse sentimento. $\mathrm{O}$ sentido do amor configurado nessa visão se revela em seu aspecto mais pragmático e, nesse caso, à medida que a presença constante da pessoa amada se verifica, o amor passa a sofrer lentamente seu desgaste e sua morte.

No entanto, há uma pista no conto que o narrador deixa em suspenso. Trata-se do "pacto da meia-noite", citado anteriormente. Esse pacto deixa entrever algo que está relacionado às identidades masculina e feminina. Num primeiro momento, o narrador indica o relógio: "São dez horas da noite" (1997, p. 111); depois: "Ela olha para o relógio e percebe que já passou das onze horas" (1997, p. 113); e finalmente: "Então ele olha para o relógio e vê que faltam apenas quinze minutos para a meianoite” (SANT’ANNA, 1997, p. 114). Essa preocupação com o relógio, por parte de ambos, sinaliza uma transformação dos estereótipos masculino e feminino.

Ao olhar para o relógio e perceber que faltam quinze minutos para meia-noite, Ferdinando pega uma revista que lê enquanto está deitado. A aproximação da meia-noite vai atenuando os comportamentos rígidos de Ferdinando, conforme afirma o narrador: "Aproxima-se a meia-noite. Marieta olha para o relógio e depois para Ferdinando. Ferdinando, [...], parece ir perdendo, aos poucos, aquela grosseria dos gestos. [...]. Marieta observa que Ferdinando, agora, parece uma moça lendo na cama" (Sant'Anna, 1997, p. 114). Essa transformação de Ferdinando deixa o leitor em suspenso sobre qual o sentido da meia-noite e por que ele muda de comportamento. Essa mutação não se verifica apenas no homem, mas também em Marieta:

Então Marieta vai ao banheiro e desfaz a maquilagem. E é como se ela houvesse deixado algo de si mesma para trás. $\mathrm{O}$ rosto de Marieta, sem os cosméticos, tem uma expressão quase dura, grosseira. $\mathrm{E}$ quando ela se abaixa, para retirar as meias, o faz sem aquele cuidado que só as mulheres sabem ter. Uma das meias se rompe e Marieta diz: - Porra. (SANT'ANNA, 1997, p. 114)

A rigidez dos padrões comportamentais se atenua com a aproximação das doze horas noturnas e o casal passa por uma confusão ou simples fusão em suas identidades. Aquilo que o narrador identificava, a partir dos pensamentos do casal, como atributos masculino e feminino passam a atingir tanto o homem quanto a mulher. Assim, a dureza e a grosseria, antes elementos próprios da masculinidade de Ferdinando, passam a ser atribuídos à Marieta. Ao soltar um palavrão, ela verbaliza e materializa essa atitude que no conto parece ser próprio daquele universo masculino. Já Ferdinando se assemelha, conforme os pensamentos de sua esposa, a uma moça lendo. Essa transformação é ainda mais profunda quando soam as doze badaladas:

Quando o relógio de parede começa a bater as doze badaladas, Marieta retira a peruca e vem depressa para o quarto. Ferdinando põe a revista de lado. E eles se olham - se olham de verdade - pela primeira 
vez nessa noite. Como se esse momento fosse o único que ainda os excitasse: as doze badaladas da meianoite. Sem a peruca, Marieta não é nem mesmo loura. Seus cabelos são cortados curtos, e negros como os de Ferdinando. Ferdinando e Marieta sorriem um para o outro e, nesse momento, são gentis e quase idênticos. Se houvesse um terceiro observador no quarto, poderia julgar que os dois são do mesmo sexo, embora difícil precisar qual sexo. E são os dois extremamente parecidos, como esses casais que, com o passar do tempo, vão roubando um do outro, simultaneamente, a fisionomia (SANT'ANNA, 1997, p. 115).

O sentido dessa fusão na identidade do casal é difícil determinar. Porém, o narrador deixa uma pista que aponta para muitos sentidos. Essa fusão pode estar direcionada para uma ideia de que com a velhice eles formam um único ser; ou, essa aparência dos dois e as fronteiras que anteriormente demarcavam as ações de cada um são rompidas de maneira que eles são "quase idênticos"; ou, ainda, transmite-se uma possibilidade de experiência de troca de gêneros. O conto constrói, pela ambiguidade em sua composição, essas possibilidades para a depreensão desses sentidos. Na cena seguinte, a narrativa proporciona uma reflexão profunda sobre os papéis masculinos e femininos cristalizados:

O relógio silenciou, depois das doze badaladas. Marieta entrega a peruca a Ferdinando e não há no seu rosto, agora, aquele sorriso de alguns segundos atrás; aquela expressão que poderia até ser confundida com amor. E Marieta diz, agora com a voz grossa de Ferdinando, que já é terça-feira. E Ferdinando, na cama, ajeitando a peruca, está deitado de modo lânguido. - Obrigada, querido - ele diz, com a voz feminina, exageradamente feminina e até vulgar, de Marieta. (SANT’ANNA, 1997, p. 115)

A inversão dos papéis é estabelecida em que Ferdinando passa a ser Marieta e vice-versa. Marieta assume o caráter do marido e em sua expressão dura não há mais o amor como anteriormente. Essa troca de papéis é importante no sentido de fazer com que cada um se sinta na pele do outro e perceba como são tratados mutuamente. $\mathrm{O}$ desfecho demonstra como as identidades se fundem num processo em que Marieta torna-se Ferdinando e vice-versa. Esse efeito é criado pelo narrador que chama os personagens pelos nomes, mas com as personalidades trocadas:

Ferdinando se joga pesadamente sobre a cama, vira-se para o lado e daqui a pouco irá roncar, como um porco. Marieta, porém, ainda faz uma tentativa, uma última tentativa. Apenas como pretexto, para conversar com Ferdinando, ela pergunta:

- Você quer a revista, querido?

- Não, mulher. Eu estou com sono - diz Ferdinando, pensando que amanhã é o seu dia de trabalhar.

- Boa noite - diz, então, Marieta, meio decepcionada.

- Boa noite - resmunga Ferdinando, mal-humorado e quase bruto porque assim são os homens. (SANT'ANNA, 1997, p. 115)

Assim, se observarmos atentamente, quem estava com a revista antes da meia-noite era o marido, Ferdinando. Porém, quando o narrador afirma que "Ferdinando se joga pesadamente sobre a cama”, é preciso lembrar que Marieta estava no banheiro e não na cama. Ferdinando já se encontrava na cama lendo a revista. Consequentemente, o narrador promove esse jogo de inversão dos papéis quando começa o diálogo dizendo que "ela pergunta: - Você quer a revista querido?”. Quem pergunta, na verdade, é Ferdinando, agora na pele de Marieta. Essa inversão faz com que Ferdinando, agora como uma mulher, corra atrás de Marieta que, por sua vez, agora age como homem e marido. Desse modo, ele sente na pele a indiferença como tratou a mulher anteriormente. 
Dentro dessa perspectiva de constituição de gêneros, a socióloga francesa Elisabeth Badinter, em sua obra Um é outro, discute essas fronteiras de marcação entre a atuação masculina e feminina. Pela leitura de Goldenberg, esta depreende que homens e mulheres estariam cada vez mais próximos e indiferenciados, sem traços exclusivos para um ou outro:

Os estereótipos do homem viril e da mulher feminina estão pulverizados. Não há mais um modelo obrigatório, mas uma infinidade de modelos possíveis. Cada um se atém à sua particularidade, à sua própria dosagem de feminilidade e masculinidade. As diferenças necessárias para a sedução se estabelecem na intimidade do casal (BADINTER, 1986 apud GOLDENBERG, 2000, p. 35).

A quebra dos padrões de masculinidade hegemônica corrobora para a multiplicidade de caminhos possíveis para a constituição masculina. Isso explica, em alguma medida, a mutação ocorrida no conto entre Marieta e Ferdinando. De fato, após a transformação, os estereótipos de masculinidade e feminilidade perdem todo o sentido ou, ao menos, passam a não ser atributos exclusivos de um ou outro gênero. A multiplicidade pode, todavia, configurar uma crise para aqueles mais apegados aos modelos preestabelecidos. Os estudos de gênero têm possibilitado, portanto, repensar os modelos cristalizados pela hegemonia: "o poder do macho passou a ser questionado, ou melhor, problematizado por homens e mulheres” (GOLDENBERG, 2000, p. 36).

Conclui-se que o efeito dessa inversão dos papéis, dentro do conto, é importante na depreensão dos perfis masculinos e femininos, propondo uma reflexão sobre a natureza artificial desses comportamentos. $O$ perfil de Marieta, agora na identidade de Ferdinando, reproduz um determinado modelo de masculinidade em que o homem se apresenta ou se posiciona como "bruto". Já Ferdinando, como esposa e mulher, ao tentar dialogar com o marido na pele de Marieta, recebe sua indiferença e desprezo. Diante disso, a narrativa demonstra, por meio de uma inversão insólita, a artificialidade desses padrões comportamentais, promovendo uma leitura reflexiva desse assunto inerente à perspectiva sobre a construção de gêneros.

\section{REFERÊNCIAS}

ALMEIDA, Maria Isabel Mendes de. Masculino/Feminino: tensão insolúvel: sociedade brasileira e organização da subjetividade. Rio de Janeiro: Rocco, 1996.

BARD, Christine. A virilidade no espelho das mulheres. In: COURBAIN, Alain; COURTINE, Jean-Jacques; VIGARELLO, Georges. História da virilidade: a virilidade em crise? V 3. Trad. Noéli Correia de Mello Sobrinho; Thiago de Abreu; Lima Florêncio. Petrópolis: Vozes, 2013.

BAUMAN, Zygmunt. Amor líquido: sobre a fragilidade dos laços humanos. Trad. Carlos Alberto Medeiros. Rio de Janeiro: Jorge Zahar, 2004.

BRUCKNER, Pascal. O paradoxo amoroso: ensaio sobre as metamorfoses da experiência amorosa. 2 ed. Trad. Rejane Janowitzer. Rio de Janeiro: Difel, 2014

GOLDENBERG, Mirian (Org.). O macho em crise: um tema em debate dentro e fora da academia. In:_. Os novos desejos: das academias de musculação às agências de encontros. Rio de Janeiro: Record, 2000 .

SANT’ANNA, Sérgio. Contos e Novelas reunidos. São Paulo: Companhia das Letras, 1997. 